\title{
WEMINO Syndrome with Skew Deviation and Facial Palsy
}

\author{
Hiromasa Tsuda, Kazuhiro Kamata, Kozue Tanaka and Shuji Kishida
}

Key words: concomitant skew deviation, magnetic resonance imaging (MRI), medial longitudinal fasciculus (MLF), peripheral facial palsy, pontine tegmentum infarction, wall-eyed monocular internuclear ophthalmoplegia

(Intern Med 50: 2435-2436, 2011)

(DOI: 10.2169/internalmedicine.50.6226)

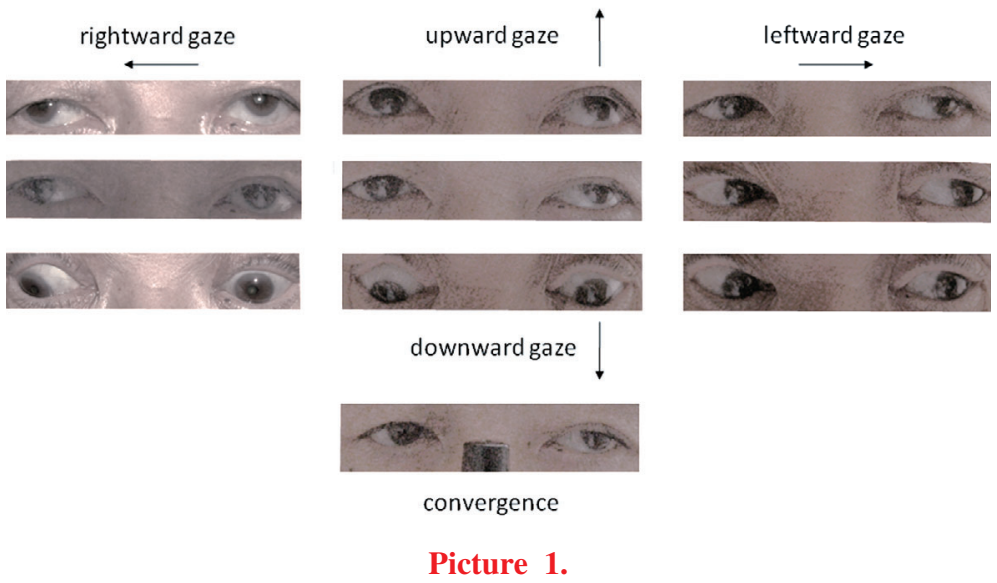

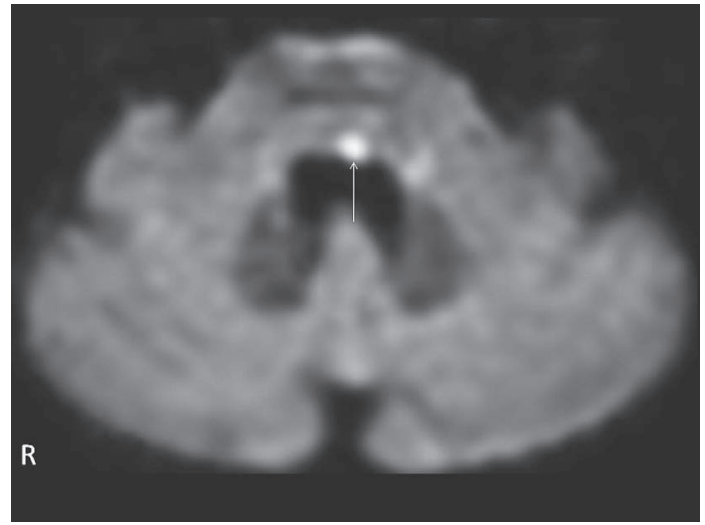

Picture 2.

A 79-year-old man with diabetes mellitus abruptly developed concomitant skew deviation (SD) with left-sided hypertropia and normal ocular torsion, and wall-eyed monocular internuclear ophthalmoplegia syndrome (WEMINO), consisting of severe restriction of adduction and convergence, and exotropia in the left eye (Picture 1). Furthermore, left-sided peripheral facial palsy was observed. Diffusionweighted magnetic resonance imaging demonstrated leftsided paramedian pontine tegmentum infarction (Picture 2, arrow), which can involve the medial longitudinal fasciculus (MLF) and the facial nerve. By administration of an anti-platelet agent, these symptoms were resolved within 2 weeks.

WEMINO is defined as unilateral internuclear ophthalmoplegia (INO) with ipsilateral exotropia, and its precise etiology remains unclear (1). SD is frequently associated with INO, because damage to vestibulo-ocular fibers in MLF can cause SD (2). However, to date there has been only one reported case of WEMINO with SD, which was caused by unilateral MLF infarction(1). Here, we emphasize that WEMINO with SD is a useful sign of unilateral MLF involvement.

The authors state that they have no Conflict of Interest (COI). 
Intern Med 50: 2435-2436, 2011 DOI: 10.2169/internalmedicine.50.6226

\section{References}

1. Jeon SB, Chung SJ, Ahn H, Lee JH, Jung JM, Lee MC. Wall-eyed monocular internuclear ophthalmoplegia (WEMINO) with contrav- ersive ocular tilt reaction. J Clin Neurol 1: 101-103, 2005.

2. Keane JR. Ocular skew deviation. Analysis of 100 cases. Arch Neurol 32: 185-190, 1975.

(C) 2011 The Japanese Society of Internal Medicine http://www.naika.or.jp/imindex.html 